\title{
Lutar por saúde é lutar por reforma agrária: estudo sobre práticas de saúde no Movimento dos Trabalhadores Rurais Sem Terra
}

\section{Struggling for health is struggling for agrarian reform: a study on health practices within the Brazil's Landless Workers' Movement}

\author{
Bianca Rückert \\ Fundação Oswaldo Cruz. Instituto René Rachou. Grupo de \\ pesquisa em Políticas Públicas e Direitos Humanos em Saúde e \\ Saneamento. Belo Horizonte, MG, Brasil. \\ E-mail: biaruckertळyahoo.com.br
}

\section{Antônia Vitória Soares Aranha}

Universidade Federal de Minas Gerais. Faculdade de Educação. Belo Horizonte, MG, Brasil.

E-mail: antoniavitoria®uol.com.br

\section{Resumo}

Este estudo de natureza qualitativa investigou práticas de saúdeem assentamentos e acampamentos do Movimento dos Trabalhadores Rurais Sem Terra, o MST, na região do Vale do Rio Doce, Minas Gerais, Brasil. Buscou-se identificar práticas condizentes com o ideal de saúde do MST, o debate de normas e valores e possíveis renormalizações, contando com o aporte teórico da saúde coletiva e da ergologia. As atividades investigadas foram: agricultura ecológica, trabalho docente que envolvia ações de saúde e ambiente e cuidado. Os resultados evidenciaram valores relacionados à luta pela reforma agrária e pela transformação da sociedade, à valorização das técnicas e dos saberes populares e à promoção da autonomia dos trabalhadores rurais. Percebeu-se, em alguma medida, a incorporação do projeto/herança da saúde do MST, que se mostrou mais efetiva, à medida que atinge os coletivos, evidenciando que a instauração de novas normas de saúde passa pela organização política dos assentamentos e acampamentos de reforma agrária. Palavras-chave: Atividade; Conhecimentos, Atitudes e Prática em Saúde; Promoção da Saúde; Saúde da População Rural.

\section{Correspondência}




\section{Introdução}

This qualitative study investigated health practices in settlements and camps of Brazil's Landless Workers' Movement (MST) in the region of Vale do Rio Doce, Minas Gerais, Brazil. We sought to identify health care practices consistent with MST's health care objectives, debate on norms and values and possible renormalizations within this framework, using Collective Health and Ergology as theoretical bases. The investigated activities were: agroecological farming, teaching activities involving health and environment actions, as well as health care activities. The results indicate values related to the struggle for agrarian reform and for the transformation of society, but also related both to the valorization of popular health care practices and to the development of the autonomy of rural workers. The incorporation of the project/health inheritance of MST, to some extent, proved to be more effective, as it reaches the collective movements, demonstrating that establishing new health standards involves the political organization of settlements and agrarian reform camps.

Keywords: Activity; Health Knowledge, Actions on Health Care; Health Promotion; Health of Rural Population.
Muitos são os desafios enfrentados pela população do campo por garantia de condições de vida e saúde, que passa pela estrutura fundiária brasileira fortemente desigual, pelos baixos índices de escolaridade, moradias inadequadas, falta de saneamento básico, baixa renda, entre outros, que se somam à incipiente participação dessa população na construção de políticas públicas (Brasil, 2013). Em relação às condições de saúde, destacam-se as doenças relacionadas ao trabalho, em especial as intoxicações por agrotóxicos, a prevalência de doenças infectoparasitárias, alta mortalidade infantil e dificuldades de acesso aos serviços de saúde, evidenciando a existência de iniquidades entre as populações do campo (Brasil, 2013; Pinheiro et al., 2009).

Em resposta a esses desafios, observa-se um encontro crescente entre diferentes atores na construção de experiências articuladas ao protagonismo dos movimentos sociais do campo, seja no âmbito da saúde ambiental, da valorização de práticas e conhecimentos tradicionais ou da promoção e educação em saúde. Para Carneiro, Burigo e Dias (2012, p. 697), tais ações "têm levado a maior autonomia dos territórios e devem nortear não apenas políticas públicas promotoras da saúde do campo, como também a construção de políticas de saúde do campo". Como exemplo, destaca-se a construção da Política Nacional de Saúde Integral das Populações do Campo, da Floresta e das Águas, que expressa o desafio de garantir os princípios do SUS para essas populações, de forma a incluir suas peculiaridades e especificidades (Brasil, 2013).

Nessa perspectiva, reconhecem-se algumas experiências protagonizadas pelo Movimento dos Trabalhadores Rurais Sem Terra, o MST (2010, p. 1), um movimento social de massas de caráter autônomo, sindical e político que visa "articular e organizar os trabalhadores rurais e a sociedade para conquistar a Reforma Agrária e um Projeto Popular para o Brasil”. Fundado em 1984, organizase atualmente em 23 estados e no Distrito Federal.

Para compreender o processo de formação do MST é necessário lembrar a história da concentração de terras no Brasil e das diversas manifestações e movimentos de luta pela terra (Fernandes, 
200o). Também é necessário compreender como a concentração de terras se acentuou nas últimas décadas pelo processo conhecido como "modernização conservadora”, que expulsou grandes contingentes populacionais do campo para as cidades e regiões de fronteiras do país, em busca de terra e trabalho. No entanto, parte dos camponeses resistiu em seus territórios e buscou formas de luta pela terra, gerando a base social do MST (Stedile; Fernandes, 1999).

Embora a fundação oficial do MST seja datada de 1984, por ocasião do seu primeiro encontro nacional, sua origem ocorreu antes, a partir de diversas experiências de luta por terra na região Centro-Sul do Brasil. Além da resistência dos camponeses à modernização conservadora, outros elementos que contribuíram para a gênese do MST foram o fator ideológico, a partir da influência do trabalho realizado pela Comissão Pastoral da Terra (CPT), e o contexto de lutas pela redemocratização do país (Stedile; Fernandes, 1999).

Apesar de surgir como movimento de luta por terra, o MST percebeu a necessidade de lutar também por uma série de políticas para o campo, como crédito para produção, infraestrutura, habitação, educação, saúde, cultura, entre outros. Demandou-se, assim, uma organização maior para que sua luta agregasse um elemento político e se transformasse em luta pela reforma agrária (Stedile; Fernandes, 1999). Para isso, sua base social se organiza em instâncias representativas, como núcleo de famílias, coordenação de área, coordenações regionais, estaduais e nacionais, compondo uma estrutura organizativa. De forma transversal a essas instâncias, são compostos os setores para a realização de tarefas e discussões específicas.

Uma dessas instâncias é o Setor de Saúde, que possui como objetivos o enfrentamento ao modelo biomédico de saúde e ao agronegócio, a luta pelo direito à saúde e pela valorização do cuidado e das práticas populares, e o incentivo à participação dos militantes no conjunto do movimento (MST, 2007). Embora as equipes de saúde se organizem desde as primeiras ocupações de terra, foi em 1995 que o tema da saúde entrou em pauta, a partir da necessidade de desenvolver as práticas para além de uma demanda imediata. Em 1998 organizou-se o setor, segundo os princípios organizativos do
MST. A partir de então, propôs-se a apropriação dos referenciais orientadores do Movimento da Reforma da Sanitária, passando a incorporar elementos como direito à saúde, educação em saúde, vida saudável e sua relação com a transformação social (Daros; Dellazeri; Andreatta, 2007).

Nessa perspectiva, o Setor de Saúde busca a construção de experiências que expressam a saúde como resultado da melhoria das condições de vida, do acesso à terra e à reforma agrária, ressaltando a importância do saneamento, da moradia, do incentivo à produção agrícola, da educação e do acesso aos serviços de saúde. Tais experiências buscam, ainda, considerar as formas de cuidado à saúde das famílias, visando o reconhecimento e valorização desses saberes.

Entretanto, o Coletivo Nacional de Saúde do MST reconhece que pensar a saúde no seu conceito ampliado, a partir da qualidade de vida e das necessidades da população do campo, é um enfoque não praticado na sociedade e no conjunto do movimento. A visão assistencialista de que saúde é cuidar das pessoas doentes, seja nas áreas, seja nas mobilizações, ainda é bastante frequente e foi percebida em estudos como os de Carneiro (2007) e Scopinho (2010).

De acordo com a ergologia, há sempre uma lacuna entre o trabalho pensado teoricamente, antecipadamente (trabalho prescrito) e aquele realizado por determinada pessoa em um lugar particular (trabalho real). Consequentemente, toda atividade do trabalho é, em alguma medida, a adesão a uma norma antecedente e, em outra, a construção de novas normas(Schwartz, 2003).

Uma vez que as normas antecedentes por si só são insuficientes para prever o que vai se passar no trabalho, na atividade o sujeito busca gerir as infidelidades do meio, fazendo "uso de suas próprias capacidades, de seus próprios recursos e suas próprias escolhas" de forma a preencher esse "vazio de normas". Há, com isso, um esforço para se reorganizar - ainda que minimamente - o meio ao redor das normas próprias (renormalização). E este, por sua vez, adquire uma dimensão ressingularizada. Cada pessoa reage ao vazio de normas de forma diferenciada e usa, para isso, sua própria história e seus próprios valores (Schwartz; Durrive, 2010, p. 190). 
Desse modo, a distância entre o trabalho prescrito e o trabalho real é percebida não como uma ausência de racionalidade, mas como diferentes racionalidades em jogo na atividade. 0 trabalho é, assim, encontro de valores, um debate de normas que ocorrem mesmo na menor das atividades, e depende de permanente arbitragem entre as normas existentes na sociedade e aquelas próprias dos sujeitos que trabalham. Para Schwartz e Durrive (2010), tais debates, por serem escolhas regidas por valores, consistem em opções políticas.

Neste artigo, apresentamos resultados da pesquisa cujo foco foi investigar práticas de saúde em assentamentos e acampamentos do MST na região do Vale do Rio Doce, Minas Gerais, Brasil. Considerando o projeto de saúde do MST como norma antecedente, buscamos apresentar como esse ideal se apresenta em práticas de saúde, quais suas particularidades e quais os confrontos de normas e valores nelas inscritos.

Partimos do pressuposto de que os valores propostos pelo MST para a luta por saúde de alguma forma repercutem nas práticas desenvolvidas pelos trabalhadores assentados e acampados. Este estudo permitiu aprofundar o conhecimento sobre as experiências de saúde produzidas em áreas de reforma agrária e favoreceu a compreensão das possibilidades de renormalização das normas biomédicas, dos desafios e avanços desse processo.

\section{Aspectos metodológicos}

Nesta pesquisa nos baseamos na metodologia de investigação qualitativa, em especial no estudo de caso e no referencial metodológico da ergologia. Esta consiste em uma abordagem que considera a atividade do trabalho em sua perspectiva concreta - a experiência real - desenvolvida por um sujeito situado histórica e antropologicamente. Nessa perspectiva, a dialética do singular e do geral pode ser apreciada: é o que Schwartz e Durrive (2010) chamam de "o ponto de vista da atividade".
O Movimento Sem Terra na região do Vale do Rio Doce foi fundado no ano de 1993 e organiza atualmente cerca de mil famílias Sem Terra ${ }^{1}$, distribuídas em treze assentamentos e sete acampamentos. A escolha da região do Vale do Rio Doce como objeto a ser estudado obedeceu aos seguintes critérios: (1) possuir áreas do MST e estar localizada no estado de Minas Gerais; (2) ser referência na organização das ações de saúde para as demais regiões; (3) ter autorização do MST e da coordenação regional para realização da pesquisa.

A pesquisa documental foi realizada com base no acervo do Coletivo Nacional de Saúde do MST, do qual foram selecionados documentos que apresentavam informações sobre as estratégias e práticas de saúde no MST.

Para o trabalho de campo, o ponto de partida foi uma entrevista coletiva com o Setor de Saúde Regional Vale do Rio Doce, a qual durou aproximadamente 90 minutos e contou com oito participantes, um homem e sete mulheres, com idades entre 28 e 56 anos. A entrevista coletiva teve como objetivo perceber como os trabalhadores compreendem a saúde tal como proposta pelo MST e apontar práticas desenvolvidas na região que são condizentes com esse ideal de saúde. Para isso, foi solicitado aos participantes que apresentassem um desenho ou objeto que representasse o conceito de saúde do MST e explicassem o porquê da sua escolha. Em seguida, realizou-se a discussão sobre o conceito de saúde do MST, seguido de levantamento das práticas de saúde na região, bem como priorização destas para investigação posterior.

Em um segundo momento, iniciou-se a investigação sobre as práticas indicadas, que ocorreu por meio da observação participante e entrevista semiestruturada com seus responsáveis. Essa fase da pesquisa foi realizada por meio de seis visitas às áreas escolhidas com duração média de quatro dias cada. Participaram ao todo nove mulheres e um homem, com idade entre 41 e 60 anos, provenientes de seis áreas de reforma agrária. Na observação

\footnotetext{
10 termo "Sem Terra" é utilizado para expressar uma "identidade historicamente construída, primeiro como afirmação de uma condição social: sem-terra, e aos poucos não mais como circunstância de vida a ser superada, mas sim como uma identidade de cultivo: somos Sem Terra do MST" (Cerioli; Caldart, 2005, p. 200). Por esse motivo, neste artigo, o termo Sem Terra (maiúsculo e sem hífen) é utilizado para se referir aos militantes do MST.
} 
participante enfatizou-se a observação das práticas desenvolvidas, os seus contextos, a participação das pessoas, a relação com os processos organizativos e os principais impactos dessas ações. 0 roteiro de entrevista foi construído na forma de tópico guia e contemplou questões sobre o trabalho investigado, seu histórico, motivações, técnicas utilizadas e saberes mobilizados.

Atendendo às diretrizes e normas da Resolução no 196/96 do Conselho Nacional de Saúde, a pesquisa foi conduzida de acordo com os padrões éticos, submetida ao CEP/UFMG Protocolo CAAEo114.0.203.00o-11, e aprovada em 14 de junho de 2011 (Brasil, 1996). Todos os participantes assinaram o Termo de Consentimento Livre e Esclarecido. A identidade dos participantes da pesquisa foi preservada e seus nomes alterados para a sigla ST (Sem Terra), acompanhada de numeração crescente.

Para a produção teórica, de posse do conjunto do material da entrevista coletiva, da observação participante e da entrevista semiestruturada, foi desenvolvida "análise de conteúdo construtiva interpretativa” (González Rey, 2005). Por esse método, os resultados são aglutinados em eixos de produção teórica, nos quais se buscou considerar as singularidades e generalidades dos participantes e suas práticas. Os elementos coletados foram confrontados com a análise dos documentos e o referencial teórico da ergologia e da saúde coletiva, em um movimento de aproximação e diálogo entre teórico e empírico. Na próxima seção apresentamos a caracterização geral das práticas de saúde, bem como os principais resultados da análise.

\section{Resultados e discussão}

\section{Caracterização das práticas de saúde investigadas}

No início do trabalho de campo, a entrevista coletiva forneceu-nos argumentos sobre como o Setor de Saúde Regional compreende o conceito de Saúde do MST, que corresponde ao acesso à terra; à segurança alimentar; às plantas medicinais e medicina natural; ao bem-estar; ao cuidado; ao diálogo; à construção de novos valores; às novas relações; ao cuidado com o meio ambiente e com os recursos naturais; à educação e à formação; à luta contra o agronegócio; e à luta pela construção de um projeto popular.

Em um segundo momento da entrevista coletiva, realizou-se um levantamento das ações de saúde desenvolvidas nas áreas do MST, que consistiam em: produção saudável; ações envolvendo saúde e ambiente nas escolas; trabalho de cuidado desenvolvido pelas próprias integrantes do Setor Regional de Saúde - ou Coletivo de Mulheres Cuidadoras -; ações de formação em saúde ambiental; ações de formação envolvendo a juventude e as mulheres; atendimentos de saúde promovidos por profissionais do SUS nas áreas de reforma agrária. Para fins de investigação qualitativa, foram escolhidas as três primeiras práticas apresentadas.

As experiências de produção saudável investigadas eram desenvolvidas por pessoas dos assentamentos Oziel Alves Pereira (Governador Valadares) e $1^{0}$ de Junho (Tumiritinga). No Assentamento $1^{\circ}$ de Junho, ST1 e ST2 manejam práticas de homeopatia e radiestesia na agricultura e na produção animal, desenvolvem experiências de horta orgânica e preservação de sementes crioulas. Ambos utilizam seus conhecimentos também no cuidado com a saúde humana. Especialmente ST2 desenvolve experiências de reflorestamento de áreas degradadas com espécies nativas e preservação de nascentes.

No assentamento Oziel Alves Pereira, ST3 desenvolve produção diversificada, de base ecológica e integração dos subsistemas produtivos. Apenas na produção animal ainda utiliza produtos agroquímicos. Diferencia-se por garantir a produção de grande parte dos alimentos consumidos pela família e comercializar a produção excedente.

As experiências de educação em saúde e ambiente investigadas eram realizadas na escola do assentamento $1^{\circ}$ de Junho (Tumiritinga), na qual se destacava o trabalho de ST4, e na escola do acampamento Juscelino dos Santos (Frei Inocêncio), em que sobressaía o trabalho de $\mathrm{ST}_{5}$. Em ambas as escolas identificamos o desenvolvimento de sistematização de saberes da comunidade e oficinas sobre plantas medicinais, agricultura ecológica e alimentação saudável, além de pesquisas participativas sobre estado de saúde da comunidade. Na escola do $1^{\circ}$ de Junho identificamos ainda ações de reflorestamento. Já na escola do Juscelino dos 
Santos, além das estratégias citadas, constatamos a realização de oficinas sobre saúde e sexualidade.

Por fim, a partir de 2010, o Coletivo de Mulheres Cuidadoras passou a se encontrar regularmente para discutir o processo organizativo do setor de saúde, socializar saberes populares e tradicionais de saúde e para que as integrantes pudessem cuidar umas das outras. Passaram a cuidar da saúde das famílias assentadas e acampadas na região, sobretudo das mulheres. Utilizam plantas medicinais, fitoterapia popular, geoterapia, radiestesia, alimentação saudável, florais, homeopatia, reiki e aromaterapia. Nesse contexto destacava-se o trabalho de cuidados desenvolvido por ST6, ST7, ST8 (Assentamento Ulysses de Oliveira, Jampruca), ST9 (Acampamento Partilha, Coronel Fabriciano), ST1o (Acampamento Padre Gino, Frei Inocêncio), ST11 (Assentamento Barro Azul, Governador Valadares), ST12 e ST13 (Assentamento Oziel Alves, Governador Valadares).

Sem desconsiderar as especificidades inerentes a cada atividade pesquisada - cuidado em saúde, agricultura e docência -, na produção teórica buscouse identificar as singularidades e as generalidades sobre o debate de normas e valores em saúde nelas inscritos. Como resultado, foram criados os eixos teóricos: agroecologia como estratégia de promoção da saúde na reforma agrária; educação e saúde como prática de liberdade; e saúde como capacidade de lutar. Ressalta-se que cada eixo teórico aborda aspectos inerentes ao conjunto das atividades investigadas.

\section{Agroecologia como estratégia de promoção da saúde na reforma agrária}

O primeiro aspecto que se destaca na análise sobre as práticas de saúde refere-se à adoção de valores relacionados à produção de base ecológica, ao cuidado com o ambiente e com os recursos naturais e ao resgate da biodiversidade, conforme expresso nos depoimentos dos participantes da pesquisa:

Quando as pessoas aprendem que precisam de uma água pura, de qualidade, que elas precisam de um remédio de qualidade, aí elas aprendem a preservar também, a cuidar da nascente, a não jogar o lixo pra todo lado, a fazer uma horta. [...] Então, o tratamento também é isso. (ST6)

São coisas que você tem que resgatar [plantas medicinais], que estão sumindo do mapa. (ST2)

É gratificante o resultado, se você observar que as crianças têm preocupação de cuidar melhor das árvores, de estarem plantando, de estarem levando mudas pra plantar. (ST4)

Tais práticas muitas vezes relacionam-se à produção e ao consumo de alimentos saudáveis e sem agroquímicos, como uma estratégia de promoção da saúde:

Às vezes, a gente tem uma terra fértil, uma terra boa. [...] e acaba envenenando a terra, envenenando a gente mesmo e envenenando as pessoas com as quais a gente convive, também. Então, a terra, ela é um conceito de saúde muito forte no sentido de que ela produz nossa própria alimentação. (ST12)

Quando a gente fornece um alimento sem remédio, a gente está contribuindo com todos que vão receber aquele alimento, dentro da família. (ST3)

Para Altieri (2008), milhões de pessoas em todo o mundo passam por uma crise de segurança alimentar, como resultado direto do modelo industrial de agricultura dependente do petróleo. Esse modelo, além de provocar aumento no preço dos alimentos, utiliza de forma insustentável os recursos naturais, afeta a qualidade dos alimentos e contribui para a expulsão dos agricultores de suas terras. Como alternativa, a soberania alimentar é difundida desde 1996 por organizações sociais - entre elas o MST como forma de reivindicação de medidas agrárias, agrícolas e alimentares ancoradas na proteção das agriculturas locais. Nessa perspectiva, situam-se propostas como agroecologia, circuitos curtos alimentares, reforma agrária e agricultura familiar (Marques, 2010).

Para os Sem Terra, a problemática da segurança alimentar não se reduz à simples oferta de alimentos. Pelo contrário, o MST reafirma a importância do cuidado com o ambiente e da adoção de um 
modelo de produção agrícola sustentável, conforme pronunciado no documento "Nossos compromissos com a terra e com a vida" (MST, 2010), criado em 2009. Neste, além do compromisso com a produção de alimentos saudáveis, destaca-se a preservação ambiental, a luta contra a privatização dos recursos naturais, a monocultura, os agrotóxicos, o latifúndio e a valorização da terra conquistada (MST, 2010).

Em especial na atividade agrícola, percebemos a circulação de valores relacionados à popularização e à socialização de tecnologias sociais na agricultura, o que pode ser observado principalmente por meio da socialização dos saberes e da troca de mudas, plantas medicinais, sementes e medicamentos homeopáticos com as demais pessoas do assentamento. Para ST1 e ST2, são práticas eficazes, de fácil replicação e baixo custo. Trazem como implicações certa autonomia no manejo de recursos, insumos e produtos da agricultura e, consequentemente, ampliação da autonomia dos trabalhadores rurais diante do monopólio das indústrias agroquímicas.

Nessa perspectiva, destacamos a agroecologia enquanto paradigma científico que orienta e propõe uma "ruptura com o modelo de desenvolvimento rural, baseado na monocultura, no latifúndio, no agronegócio e na exclusão social" (Ribeiro; Ferreira; Noronha, 2007, p. 258). Diversas iniciativas de agroecologia são desenvolvidas nos assentamentos e acampamentos do MST. De acordo com Gaia (2008, p. 38), além da diversidade de técnicas, ressalta-se a importância da agroecologia para o "empoderamento político dos agricultores e agricultoras, técnicos(as) e dirigentes".

Dessa forma, a agroecologia é proposta pelo MST como enfoque político, ressaltando-se a relação entre a agricultura, o modelo de desenvolvimento para o campo e a saúde. Essa relação pode ser percebida de forma especial no depoimento de uma integrante do Coletivo de Cuidadoras: Esse cuidado com o planeta, esse cuidado com o ser humano, essas novas relações. $\varepsilon$ É um projeto diferente desse capitalista mesmo (ST7).

Para o MST (2005, p. 41), essa relação deve passar por uma nova postura e uma nova visão homem/ natureza, resgatando a capacidade de dialogar com a natureza, considerando o ser humano como parte dela: "diálogo há muito tempo rompido com a imposição do sistema produtivo predador que separa o homem da natureza e tem como lógica o esgotamento de seus recursos e a exploração de homens e mulheres".

Por outro lado, evidenciamos que os participantes dessa pesquisa ainda apresentavam uma série de dificuldades referentes às práticas agroecológicas, que se relacionam principalmente à dependência de insumos (especialmente sementes industrializadas); ao uso esporádico de agroquímicos; à baixa capacitação técnica; à dependência de tecnologias externas oriundas das indústrias agroquímicas e instituições extensionista, entre outras. Essa situação é agravada pela degradação ambiental das fazendas desapropriadas, pela falta de assistência técnica nos assentamentos, pela imposição de padrões da indústria agroquímica e pela falta de incentivo - por parte das políticas públicas - à agricultura familiar e à reforma agrária, entre outros fatores.

Esses desafios geram confrontos de normas que se instauram no âmbito da atividade, relembrandonos que esta ocorre em um meio que interfere diretamente nas escolhas.

Tem um assentamento aqui vizinho [...], onde eles plantavam menos quantidade de milho do que nós, $e$ colhiam muito mais. Esta discussão às vezes vinha: "Ah, nós estamos errando na questão do plantio, porque lá [no assentamento vizinho] eles plantam em uma área menor e estão colhendo mais que nós". Mas aí a gente vai ver, e, ah, lá estão usando adubo químico. (ST2)

Tais desafios também foram apontados por Santos (2011), ao pesquisar as condições de saúde, ambiente e trabalho em um assentamento do MST no Rio de Janeiro. Os resultados dessa pesquisa evidenciam que as dificuldades do desenvolvimento da produção agrícola familiar estão relacionadas às variabilidades climáticas, à falta de crédito, às dificuldades de comercialização e à lentidão no desenvolvimento do projeto de assentamento. Outros estudos, desenvolvidos por Scopinho (2010) em assentamento do MST no estado de São Paulo e por Fontoura Júnior et al. (2012) em assentamento do MST no estado do Mato Grosso do Sul, também evidenciam a falta de políticas públicas para agricultura familiar 
e reforma agrária e seus impactos prejudiciais na saúde das famílias assentadas.

\section{Educação e saúde como prática de liberdade}

Ao investigarmos a atividade docente, observamos que as ações de saúde e ambiente se fundamentam na valorização e socialização dos saberes populares locais, na socialização de saberes e técnicas sustentáveis e saudáveis, e no estímulo ao protagonismo dos educandos. De acordo com uma das educadoras:

Quando nós chegamos aqui, por exemplo, muitas crianças não gostavam de comer taioba. [...] Eu trabalhava muito a questão da alimentação com eles, daí no ano passado nós fizemos um livrinho de receita, coletamos as receitas de cada família, como forma de incentivar a comunidade a trocar as receitas, o que cada um faz, né? (ST5)

Para outra educadora, a escola deve propiciar ao aluno a reflexão sobre o futuro do assentamento, de forma a contribuir com seu desenvolvimento. Observa-se, portanto, uma preocupação com a valorização da reforma agrária e da agricultura familiar como perspectiva de desenvolvimento para o campo.

Pela própria escola, né, pela formação dos meninos que estão em cada família, é o sonho da gente também estar criando uma escola que tenha a preocupação com a agricultura, com os problemas da agricultura, que são da terra. (ST4)

Nessa perspectiva se insere a educação do campo, que visa a valorização e a legitimidade dos protagonistas dos trabalhadores rurais enquanto produtores (as) de conhecimento que resistem e constroem outras propostas de trabalho e vida no campo e que se orientam por uma perspectiva de transformação social (Caldart, 2009). Ela propõe uma preparação para o trabalho que tenha como perspectiva a construção de uma nova matriz tecnológica de produção, baseada na sustentabilidade, nas relações de cooperação e na agroecologia.

Apesar de valorizar a escola, o MST "luta para que a concepção de educação que oriente suas práticas se descentre da escola, não fique refém de sua lógica constitutiva, exatamente para poder ir bem além dela enquanto projeto educativo" (Caldart, 2009, p. 38). Para isso, busca-se desenvolver atividades relacionadas às questões concretas da vida da comunidade: Além de trabalhar em sala de aula, o que eles podem levar de concreto pra casa? ( $\mathrm{ST}_{5}$ ).

Nessa perspectiva, propõe-se a educação sobre bases emancipatórias, que apresenta a realidade social como ponto de partida, buscando desvelar as relações que a compõem, determinam e condicionam, de forma a transformar essa realidade a partir da "construção de sujeitos e projetos societários transformadores”. Do contrário, a educação atém-se a finalidades reprodutivistas (Morosini; Fonseca; Pereira, 2009, p. 157).

Assim, a educação do campo merece ser destacada por sua contribuição na construção de práticas de saúde no MST. Entretanto, conforme destacado pelo Coletivo Nacional de Saúde, as escolas são pouco exploradas como espaços de promoção da saúde nos assentamentos e acampamentos (MST, 2005).

Destacamos também o potencial pedagógico do trabalho desenvolvido pelas mulheres do Coletivo Regional que, por meio da atividade do cuidado, buscam contribuir para que os Sem Terra enfrentem os potenciais de adoecimento na reforma agrária.

Aqui é uma região que usa muito veneno. [...] Muita gente chega intoxicada, com dor de cabeça, com ferida no corpo, mas não aceita que é do agrotóxico. Agora... tem uma família que entendeu que era. [...] nós fomos conversando com a família, pedindo pra fazer uma experiência junto com eles. Quando eles chegavam [molhados] de veneno, daí a gente observava. [...] daí a pouco o menino tinha crise. Eles mesmos foram compreendendo, e daí não usaram mais o veneno. (ST6)

Conforme ressaltado, a atividade do cuidado desenvolvida pelas mulheres do Coletivo Regional busca promover a valorização do cuidado com o ambiente, a alimentação saudável e o estímulo à agroecologia. Busca descentrar-se da ação assistencial em saúde, avançar no sentido de promoção da autonomia e construir uma visão sobre a saúde na sua relação com os determinantes sociais. 
Para o MST (2005), a saúde passa a adotar uma nova postura, coerente com os princípios da saúde como direito em seu conceito ampliado, e da educação em uma perspectiva emancipadora.

Eu acho que isto é muito importante: não falar pra pessoa que isso está errado, mas deixar a pessoa perceber. [...] Isso leva mais tempo, mas é uma coisa em que eu acredito: a educação popular. [...] É melhor do que a gente ficar arrumando remédio pra ela, né? [...] uma das coisas mais positivas a gente saber que as pessoas aprenderam a lidar com a própria saúde, né? Lidar com a vida. (ST6)

Mas, para além do cuidado individual, o Coletivo de Cuidadoras propõe ações coletivas que envolvem as famílias assentadas e acampadas, em especial as mulheres Sem Terra, em uma perspectiva de socialização e valorização dos saberes em saúde e agroecologia. Entre as atividades desenvolvidas podemos citar as oficinas de saúde nos assentamentos e acampamentos, que articulam os saberes das plantas medicinais com os saberes da alimentação saudável; oficinas de geoterapia, com o objetivo de sensibilizar as mulheres para as questões da saúde e a importância do cuidado com os recursos naturais; e o curso de plantas medicinais e terapias naturais.

Quando o Coletivo de Cuidadoras ou as educadoras das escolas chamam as famílias para discutir saúde e ambiente, trazem para a esfera coletiva problemas que normalmente são resolvidos no plano individual. Na perspectiva crítica da educação em saúde, pressupõe-se que os sujeitos sejam abordados enquanto indivíduos e coletividades, uma vez que os problemas de saúde não são vividos isoladamente. Por isso, a solução dos problemas não passa apenas pela mudança de comportamento individual, mas por estratégias de atuação na vida das coletividades, ou seja, no âmbito das necessidades sociais (Stotz, 2007).

Há, portanto, uma dimensão forte dos saberes que se inscrevem na normatividade dessas práticas. De acordo com Schwartz (2003, p. 27), os saberes também estão na dependência do debate de normas. Uma vez que se inserem na história, eles "não podem se desenvolver na neutralidade, assim como nós não podemos ser neutros quando fazemos nossa própria história”. E a ergologia nos leva a interrogar a intencionalidade desses saberes socializados e transmitidos na sociedade. "Esses saberes, não neutros, gerados dentro da história do trabalho são saberes para quem, para quê?" (Schwartz, 2003, p. 28).

Podemos afirmar que tais experiências articulam a dinâmica da produção e da circulação de saberes aos horizontes sociais mais amplos a serem perseguidos na luta pela reforma agrária do MST ou, conforme apresentado por Morosini, Fonseca e Pereira (2009, p. 157), com "projetos societários transformadores".

\section{Saúde como capacidade de lutar}

Realizadas as devidas considerações acerca dos valores investidos na atividade agrícola, há que se considerar a necessidade de circulação desses valores entre as famílias dos assentamentos, no sentido de propiciar as devidas renormalizações no âmbito da atividade. Entretanto, de modo geral, a atividade agrícola era desenvolvida de forma isolada, sem envolver o conjunto das famílias. Aqui destacamos os desafios inerentes à própria organização dos assentamentos para o fortalecimento da agroecologia.

Tais desafios atingem diretamente as ações desenvolvidas nas escolas dos assentamentos e acampamentos, uma vez que a educação do campo propõe uma estreita relação entre a escola e a comunidade. Conforme ST4, no assentamento $1^{\circ}$ de Junho: A gente tenta levar uma discussão, porque agora, com o desfalque da cooperativa e das associações, a escola é a que consegue reunir com um objetivo comum (ST4).

A partir da experiência do $1^{\circ}$ de Junho, percebemos que a escola "acompanha" o processo organizativo do assentamento - quando há iniciativa na comunidade, tais ações repercutem para dentro da escola. Por outro lado, na educação do campo, a escola sozinha não transforma a realidade, ela integra o processo de organização dos assentamentos.

Ressalta-se, assim, o papel da organização coletiva na construção das atividades investigadas. Para o MST (2005, p. 5), a saúde se liga à luta pela reforma agrária e a todas as lutas por melhores 
condições de vida. Nessa luta social, as famílias incorporam todas as suas dimensões: produção, saúde, educação, cultura, lazer, e "na condição de Sem Terra são lutadores da saúde no sentido mais profundo desse significado". Com isso, a saúde passa a ser uma tarefa de toda a organização - e não somente do setor -, cultivada por cada militante. No depoimento de ST7 fica explícita uma concepção de saúde que passa pelas diversas dimensões da luta pela reforma agrária.

Eu acho que a saúde é o povo construindo movimento, né? $\varepsilon$ construindo a luta. Acho que isso também é saúde, é acabar com os despejos, é conquistar a terra [...]. Porque vocêvê o povo, o cansaço [...]. Então éesse processo de despejo, de desgaste com a luta, que não saem as conquistas, né? Esse INCRA que não faz... Então essa concentração de terra é uma doença, é uma doença do mundo. O lixo é uma doença do mundo e a concentração também, de terra, de poder. $\varepsilon$ coloquei que eu acho que são as nossas plantas, os alimentos, o povo... Eu vinha pensando que estar junto é bom demais, a gente fica mais forte, fica mais saudável. E o estudo também, né? A importância de a gente estar fazendo o estudo, comendo bem, comendo as coisas que nós plantamos, que o povo planta na terra, trabalha, enfim. (ST7)

Se analisarmos novamente os "eixos da saúde" construídos pelo Setor Regional, percebemos que, entre outros fatores, a saúde passa pela luta por reforma agrária e por um projeto popular. Essa é uma dimensão que se aproxima bastante da concepção formulada pelo Coletivo Nacional de Saúde, na qual "ter saúde é ter a possibilidade de lutar contra o que nos agride e nos ameaça, inclusive a doença. E a intervenção em saúde deve, portanto, fortalecer essa capacidade de lutar" (MST, 2007, p. 1).

Tal perspectiva dialoga com a dimensão normativa da vida de Georges Canguilhem (2009, p. 151-152), para o qual o homem é um ser que busca sempre estabelecer novos valores no meio. Ter saúde, para este autor, não é apenas se adaptar às exigências do meio, é ser normativo, é abusar do meio e poder ficar doente: "a possibilidade de abusar da saúde faz parte da saúde”. Nessa concepção, a saúde expressa segurança na vida, uma vez que representa uma maneira de "abordar a existência com uma sensação não apenas de possuidor ou portador, mas também, se necessário, de criador de valor, de instaurador de normas vitais”. E assim propõe o ser humano como um ser para quem é possível romper e criar novas normas.

Para Schwartz e Durrive (2010, p. 81), "constatar que os trabalhadores se apropriam das normas, mascaram, transgridem, jogam com elas inventando novas normas, em resumo renormalizam permanentemente, significa que há vida, significa a possibilidade de dominar o sistema”. Do contrário, o homem é escravo do sistema.

A inserção no MST é destacada em vários estudos como potencial de fortalecimento em saúde (Carneiro, 2007; Gaia, 2005; Ricardo, 2011; Santos, 2011; Scopinho, 2010), mostrando que a história se reescreve permanentemente a partir de tensionamentos de valores e normas instaurados por grupos sociais. Novas normas de construção do social reaparecem em todos os lugares onde os grupos humanos se mobilizam para produzir (Schwartz, 2003).

Trata-se de uma contribuição importante para se compreender a experiência do MST na luta por saúde. De acordo com Carneiro (2007, p. 116), para o MST, "a saúde passa a significar conquista da luta popular". Seu processo organizativo consiste no grande diferencial de sua ação, além da politização do conceito e das ações de saúde como forma de confronto com o modelo biomédico e o complexo industrial farmacêutico. A intersetorialidade torna-se extremamente necessária para atender a diversidade de demandas que compõem a luta por saúde e melhores condições de vida. Para isso, o MST busca formar e envolver militantes nas ações de saúde.

\section{Considerações finais}

Este artigo analisou, sob o ponto de vista da atividade, os valores inscritos em práticas de saúde desenvolvidas em assentamentos e acampamentos do MST na região do Vale do Rio Doce, Minas Gerais. Por meio das atividades pesquisadas - agricultura, docência e cuidado - percebemos a afirmação de valores relacionados ao cuidado com a vida e com a natureza; à valorização das técnicas e dos saberes 
populares no âmbito da agroecologia e da saúde; à promoção da autonomia; à saúde como resultado de melhores condições de vida; e à luta pela reforma agrária e pela transformação social. Tais valores, muitas vezes, encontraram terreno fértil nas relações sociais no assentamento, no acampamento, na escola e nos coletivos.

Percebemos que a busca pela renormalização das práticas pesquisadas passa por uma postura crítica paradigmática, atravessada por concepções de saúde, agricultura, relação homem/natureza, educação e ser humano. Mais do que uma crítica à concepção biomédica de saúde, elas se relacionam com os horizontes sociais mais amplos, tais como propostos pelo MST. Dessa forma, como movimento social, o MST mostra que homens e mulheres querem ser sujeitos de suas próprias normas.

Embora singulares, em alguma medida, tais atividades incorporam o projeto/herança de saúde do MST, a partir de uma relação dialética que se inscreve entre trabalhadores e movimento social. Os valores variam segundo a própria atividade, as normas antecedentes, o contexto, os trabalhadores e seus saberes e experiências. Não se trata, assim, de negar as normas antecedentes como se a atividade precisasse ser recriada a todo o momento. Tratandose de um movimento social que busca construir normas próprias, é importante sempre considerar o seu processo histórico. Nesse sentido, ressaltamos a importância de o MST continuar sistematizando experiências e elaborando referências que sirvam como orientadoras das práticas de saúde.

No entanto, se os trabalhadores investigados nos mostram que o MST constrói valores no âmbito da saúde, ainda são muitos os desafios para que a saúde como direito se efetive nos assentamentos e acampamentos da região do Vale do Rio Doce, que passa, sobretudo, pela falta de políticas de reforma agrária. Tais desafios, é importante destacar, não são exclusivos da região pesquisada.

\section{Referências}

ALTIERI, M. A. Sistema alimentar na era póspetroleira. Carta Maior, [S.l.], 22 abr. 2008. Disponível em: <bit.ly/2F5vM7O $\rangle$. Acesso em: 25 ago. 2015 .
BRASIL. Ministério da Saúde. Conselho Nacional de Saúde. Resolução n ${ }^{\circ} 196$, de 10 de outubro de 1996. Dispõe sobre os aspectos ético-legais de pesquisa em saúde. Diário Oficial [da] República Federativa do Brasil, Brasília, DF, 11 out. 1996.

BRASIL. Ministério da Saúde. Secretaria de Gestão Estratégica e Participativa. Política Nacional de Saúde Integral das Populações do Campo e da Floresta. Brasília, DF: Ministério da Saúde, 2013.

CALDART, R. S. Educação do campo: notas para uma análise de percurso. Trabalho, Educação e Saúde, Rio de Janeiro, v. 7, n. 1, p. 35-64, 2009.

CANGUILHEM, G. O normal e o patológico. Rio de Janeiro: Forense Universitária, 2009.

CARNEIRO, F. F. A saúde no campo: das políticas oficiais à experiência do MST e de famílias de "bóias-frias" em Unaí, Minas Gerais, 2005. 2005. Tese (Doutorado em Ciência Animal) - Escola de Veterinária da Universidade Federal de Minas Gerais, Belo Horizonte, 2007.

CARNEIRO, F. F.; BURIGO, A. C.; DIAS, A. P. Saúde no campo. In: CALDART, R. S. et al. Dicionário da educação do campo. Rio de Janeiro: Escola Politécnica de Saúde Joaquim Venâncio; São Paulo: Expressão Popular, 2012. p. 696-699.

CERIOLI, P. R.; CALDART, R. S. Como fazemos a escola de educação fundamental? In: ITERRA - INSTITUTO TÉCNICO DE CAPACITAÇÃO E PESQUISA NA REFORMA AGRÁRIA. Dossiê MST Escola: documentos e estudos 1990-2001. Brasília, DF: Ministério do Desenvolvimento Agrário, 2005. p. 199-231.

DAROS, D.; DELLAZERI, D. T.; ANDREATTA, M. O curso técnico em saúde comunitária do IEJC. In: ITERRA - INSTITUTO TÉCNICO DE CAPACITAÇÃO E PESQUISA NA REFORMA AGRÁRIA. O Instituto de Educação Josué de Castro e a educação profissional. Veranópolis, 2007. p. 129-177.

FERNANDES, B. M. A formação do MST no Brasil. Petrópolis: Vozes, 2000. 
Fontoura Júnior, E. E. et al. Relações de saúde e trabalho em assentamento rural do MST na região de fronteira Brasil-Paraguai. Trabalho, Educação e Saúde, Rio de Janeiro, v. 9, n. 3, p. 379-397, 2012.

GAIA, M. C. M. Saúde como prática da liberdade: as práticas de famílias em um acampamento do MST e o desenvolvimento de estratégias de educação popular em saúde. 2005. Dissertação (Mestrado em Saúde Coletiva) - Fundação Oswaldo Cruz, Belo Horizonte, 2005.

GAIA, M. C. M. Agroecologia: a resistência do camponês e da camponesa sem-terra. 2008. Monografia (Especialização em Agroecologia e Desenvolvimento Sustentável) - Centro Federal de Educação Tecnológica de Rio Pomba, Rio Pomba, 2008.

GONZÁLEZ REY, F. L. Pesquisa qualitativa em psicologia: caminhos e desafios. São Paulo: Pioneira Thomson Learning, 2005.

MARQUES, P. E. M. Embates em torno da segurança e soberania alimentar: estudo de perspectivas concorrentes. Segurança Alimentare Nutricional, Campinas, v. 17, n. 2, p. 78-87, 2010.

MOROSINI, M. V.; FONSECA, A. F.; PEREIRA, I. B. Educação em saúde. In: PEREIRA, I. B.; FRANÇA LIMA, J. C. (Org.). Dicionário de educação profissional em saúde. 2. ed. Rio de Janeiro: EPSJV, 2009. p. 153-162.

MST - Movimento dos Trabalhadores Rurais Sem Terra. Coletivo Nacional de Saúde. Relatos de experiências em saúde. Brasília, DF, 2005.

MST - Movimento dos Trabalhadores Rurais Sem Terra. Coletivo Nacional de Saúde. Boletim Informativo. Brasília, DF, 2007.

MST - Movimento dos Trabalhadores Rurais Sem Terra. Secretaria Nacional. MST: lutas e conquistas. 2. ed. São Paulo, 2010.

PINHEIRO, T. M. M. et al. Saúde no campo. Rio de Janeiro: Abrasco, 2009.

RIBEIRO, S.; FERREIRA, A. P.; NORONHA, S. Educação do campo e agroecologia. Agriculturas: Experiências em Agroecologia, Rio de Janeiro, v. 4, n. 3, p. 257-267, 2007.
RICARDO, L. M. O uso de plantas medicinais na medicina popular praticada em assentamentos do MST do estado do Rio de Janeiro: uma contribuição para o SUS. 2011. Dissertação (Mestrado em Saúde Pública) - Fundação Oswaldo Cruz, Rio Janeiro, 2011.

SANTOS, J. C. B. O movimento dos trabalhadores rurais sem-terra e as relações entre saúde, trabalho e ambiente em um assentamento rural no estado do Rio de Janeiro. 2011. Dissertação (Mestrado em Saúde Pública) - Fundação Oswaldo Cruz, Rio de Janeiro, 2011.

SCHWARTZ, Y. Trabalho e saber. Trabalho e Educação, Belo Horizonte, v. 12, n. 1, p. 20-35, 2003.

SCHWARTZ, Y.; DURRIVE, L. (Org.). Trabalho e ergologia: conversas sobre a atividade humana. 2. ed. Niterói: Universidade Federal Fluminense, 2010.

SCOPINHO, R. A. Condições de vida e saúde do trabalhador em assentamento rural. Ciência e Saúde Coletiva, Rio de Janeiro, v. 15, p. 1575-1584, jun. 2010. Suplemento 1.

STEDILE, J. P.; FERNANDES, B. M. Brava gente: a trajetória do MST e a luta pela terra no Brasil. São Paulo: Perseu Abramo, 1999.

STOTZ, E. N. Enfoques sobre educação popular e saúde. In: BRASIL. Ministério da Saúde.

Secretaria de Gestão Estratégica e Participativa. Caderno de educação popular e saúde. Brasília, DF: Ministério da Saúde, 2007. p. 46-57.

\section{Contribuição das autoras}

Rückert foi responsável pelo levantamento e análise dos dados e pela concepção, redação e revisão do artigo. Aranha foi responsável pela orientação da pesquisa e pela aprovação da versão final do artigo.

\section{Agradecimentos}

Agradecemos a Priscila Neves Silva pela leitura atenta do manuscrito.

Recebido: 02/03/2017

Reapresentado: 04/09/2017

Aprovado: $11 / 01 / 2018$ 